\title{
Effects of culling on badger abundance: implications for tuberculosis control
}

\author{
R. Woodroffe ${ }^{1,2}$, P. Gilks ${ }^{3}$, W. T. Johnston ${ }^{3}$, A. M. Le Fevre ${ }^{3 *}$, D. R. Cox ${ }^{2,4}$, C. A. Donnelly ${ }^{2,3}$, \\ F. J. Bourne ${ }^{2}$, C. L. Cheeseman ${ }^{5}$, G. Gettinby ${ }^{2,6}$, J. P. Mclnerney ${ }^{2}$ \& W. I. Morrison ${ }^{2,7}$ \\ 1 Department of Wildlife, Fish \& Conservation Biology, University of California, Davis, CA, USA \\ 2 Independent Scientific Group on Cattle TB, c/o Department for Environment, Food \& Rural Affairs, London, UK \\ 3 Department of Infectious Disease Epidemiology, Faculty of Medicine, Imperial College London, London, UK \\ 4 Nuffield College, Oxford, UK \\ 5 Central Science Laboratory, Sand Hutton, York, UK \\ 6 Department of Statistics and Modelling Science, University of Strathclyde, Glasgow, UK \\ 7 Centre for Tropical Veterinary Medicine, Royal (Dick) School of Veterinary Studies, University of Edinburgh, Midlothian, UK
}

\section{Keywords}

badger; culling; Meles meles; Mycobacterium bovis; perturbation; randomized badger

culling trial; tuberculosis; wildlife disease.

\section{Correspondence}

Rosie Woodroffe, Department of Wildlife, Fish \& Conservation Biology, University of California, One Shields Avenue, Davis, CA 95616, USA. Tel: 530754 9513; Fax: 530 7524154

Email: rwoodroffe@ucdavis.edu

*Current address: Infectious Disease Epidemiology Unit, London School of Hygiene \& Tropical Medicine, Keppel Street, London WC1E 7HT, UK.

\begin{abstract}
Culling is often considered as a tool for controlling wildlife diseases that can also infect people or livestock. Culling European badgers Meles meles can cause both positive and negative effects on the incidence of bovine tuberculosis (TB) in cattle. One factor likely to influence the outcome of different badger culling strategies for cattle TB is the reduction in badger population density achieved. However, this reduction is difficult to measure because badgers, being nocturnal and fossorial, are difficult to count. Here, we use indices of badger abundance to measure the population impacts of two culling strategies tested in Britain. The densities of badger setts and latrines recorded before culling were correlated with the densities of badgers captured on initial culls, suggesting that both were indices of actual badger abundance. Widespread 'proactive' culling was associated with a 73\% reduction in the density of badger latrines, a $69 \%$ reduction in the density of active burrows and a $73 \%$ reduction in the density of road killed badgers. This population reduction was achieved by a coordinated effort entailing widespread and repeated trapping over several years. However, this strategy caused only modest reductions in cattle TB incidence in culled areas and elevated incidence in neighbouring unculled areas. Localized 'reactive' culling caused a $26 \%$ reduction in latrine density, a $32 \%$ reduction in active burrow density and a $10 \%$ reduction in the density of road killed badgers, but apparently increased the incidence of cattle TB. These results indicate that the relationship between badger population reduction and TB transmission to cattle is strongly non linear, probably because culling prompts changes in badger behaviour that influence transmission rates. These findings raise serious questions about the capacity of badger culling to contribute to the control of cattle TB in Britain.
\end{abstract}

\section{Introduction}

Most models of infectious disease dynamics assume that contact rates between host organisms, and therefore trans mission rates, decline as host population densities are re duced; the simplest models assume that this relationship is linear (Barlow, 1996). Likewise, where a pathogen can infect more than one host species, reducing the density of one host is expected to lower the interspecific transmission rate. Because host population reduction is expected to have these twin effects, culling is often considered as a means of controlling wildlife diseases that can also infect people or livestock (e.g. Ballantyne \& O’Donoghue, 1954; Dobson \& Meagher, 1996).

In the British Isles, European badgers Meles meles are implicated in spreading Mycobacterium bovis (the causative agent of bovine tuberculosis, TB) to cattle. Badger culling has therefore formed a component of TB control policy for many years (Krebs et al., 1997).

Recent field trials investigating the impacts of badger culling on TB dynamics suggest that the relationship be tween host density and disease transmission is far from linear. Different culling strategies have been associated with both reductions and increases in the prevalence of $M$. bovis infection in badgers (Griffin et al., 2003; Woodroffe et al., $2006 b$ ) and the incidence of TB in cattle (Donnelly et al., 2003, 2006; Griffin et al., 2005). The degree of badger population reduction achieved by culling is probably one factor contributing to this variation.

Assessment of the impact of culling on badger density is impeded by badgers' secretive nocturnal behaviour. Several 
studies have demonstrated correlations between badger abundance and the densities of field signs such as setts (badger dens) and latrines (sites badgers visit regularly for scent marking), although predictive power varies between methods, sites and seasons (Tuyttens et al., 2001; Wilson et al., 2003a; Sadlier et al., 2004).

Here, we use field data to assess the impacts of culling on badger populations in Britain's Randomized Badger Culling Trial (RBCT); we also describe the capture effort entailed in achieving such impacts. These data can be used to inform the design of future TB control strategies.

\section{Methods}

\section{Overall study design}

Data collection focused on 30 areas, each measuring $c$. $100 \mathrm{~km}^{2}$ and located in regions of high TB risk to cattle (Woodroffe et al., 2006b). These 30 areas were grouped into 10 'triplets' denoted A J. Within each triplet, all three areas were simultaneously surveyed for signs of badger activity, and then randomly allocated to three treatments: wide spread 'proactive culling' (which aimed to maintain badger densities at low levels by culling across entire trial areas approximately annually); localized 'reactive culling' (which entailed one off small scale badger culling in response to specific TB outbreaks in cattle); and 'no culling' (an experi mental control).

Triplets were recruited sequentially. Initial proactive culls were conducted between 1998 and 2002. The reactive treat ment was suspended in November 2003; hence, no reactive culling was conducted in Triplet $\mathbf{J}$ (Donnelly et al., 2003). Proactive culling was completed in October 2005. Cull dates are given in Supplementary Material.

\section{Badger trapping operations}

Badgers were captured in cage traps baited with peanuts. All trapping was conducted during May January to avoid catching lactating females with dependent cubs still confined to setts (Woodroffe et al., 2005a). In proactive areas, trapping occurred across all properties to which landholders granted access. Reactive culling operations were restricted to the home ranges of badger social groups judged, from field surveys, to include land occupied by cattle herds that had experienced recent TB incidents.

Trap deployment at each capture site (usually a sett) was determined by the level of badger activity detected at the time, with the number of traps set intended to exceed the number of badgers that experienced field staff expected to capture. Traps were set after a 12 week prebaiting period. Standard operating procedures prescribed that initial proac tive culling operations be conducted over 11 consecutive nights. Both 'follow up' proactive culls and reactive culls were conducted over eight nights. Captured badgers were dispatched by gunshot; independent audit deemed dispatch 'humane' (Kirkwood, 2000) and most badgers received no detectable injuries from confinement in the trap (Woodroffe et al., 2005b). Captured animals other than badgers were released, or dispatched humanely if deemed too badly injured for release. Evidence of destruction, removal or interference with traps was recorded, as was evidence (e.g. vegetation pulled into trap) that traps had contained bad gers subsequently released by protestors.

Measures of trapping effort, capture rate and interference were derived from Defra records. Data on trap deployment, captures and trap interference were available for each day and each sett on 44 proactive and 62 reactive culling operations; summary data were available for seven addi tional proactive operations (detailed in Supplementary Ma terial). Capture rate was calculated as the number of badgers caught, divided by the number of traps available (i.e. not occupied by other species or subjected to inter ference) on a particular night.

\section{Surveys of badger activity}

Initial pre cull surveys of badger activity (denoted 'Survey One' in figures and tables) were conducted across all trial areas before treatments were allocated, on all properties to which landholders granted access (including areas where permission was given for surveying but not culling). Survey teams used 1:10000 maps to record all badger setts and latrines encountered, estimating locations on a $100 \mathrm{~m}$ grid. At each sett, observers recorded the numbers of active holes (those showing evidence of repeated recent use, often with fresh digging or tracks), and inactive holes (without evi dence of recent use, often blocked by cobwebs, accumulated leaves or other debris), as well as latrines, fresh digging and bedding. Setts were classified as 'main' or 'other' on the basis of their size, activity and location in relation to other nearby setts (Thornton, 1988); however, independent audit found that field staff appeared hesitant to identify 'main' setts (Cresswell, 2001) and so the numbers are probably under estimated. A small number of setts recorded before culling, but after treatment allocation, were excluded because survey effort was not consistent across trial areas once field staff were preparing for proactive culling. Latrine data could not be censored in the same way because mapping dates of individual latrines were not recorded.

Subsequent post cull 'follow up' surveys of badger activ ity were conducted on all accessible land (including land accessible for surveying but not culling) in sample areas, each covering $5 \%$ of a trial area. These surveys were conducted without reference to earlier maps, to ensure consistent data collection protocols across successive sur veys. Each survey covered four or six sample areas, together comprising 20 or $30 \%$ of a trial area. There was some overlap in the sample areas chosen for inclusion in succes sive surveys. Follow up surveys were conducted $c$. 2 years after completion of each initial cull, and at least every 2 years thereafter; survey dates are given in Supplementary Material. For illustrative purposes, results are quoted for the fourth survey because this was the latest to be conducted in all 10 triplets. 


\section{Bait marking}

More intensive surveys of badger activity were conducted in a subset of triplets in 2004 2005. These surveys used colour marked bait to delineate badger home ranges (Delahay et al., 2000), and are described in detail in Woodroffe et al. (2006a). Study areas of $c .16 \mathrm{~km}^{2}$ were located inside the reactive and no culling areas of Triplets $\mathrm{B}, \mathrm{D}, \mathrm{G}$ and $\mathrm{H}$. Study areas of about $24 \mathrm{~km}^{2}$ spanned the boundaries of proactive culling areas in $\mathrm{B}, \mathrm{C}, \mathrm{D}, \mathrm{G}$ and $\mathrm{H}$, allowing comparison of badger activity in $c .16 \mathrm{~km}^{2}$ of culled land with that on adjoining land. We used the number of colour marked faecal deposits (bait returns) recorded per $\mathrm{km}^{2}$ to indicate local badger activity. The unculled portion of the proactive study area in Triplet $\mathrm{G}$ was small in comparison with other study areas (containing only one badger home range, Woodroffe et al., 2006a), and the results from this area are therefore excluded.

\section{Road traffic accident survey}

The relative badger abundance was also estimated using a survey of badgers killed in road traffic accidents, conducted primarily to investigate regional patterns of $M$. bovis infec tion (Bourne et al., 1998). This survey was conducted during 20022005 in seven counties, and covered all trial areas of Triplets A, B, C, D, F and J.

The numbers of carcasses retrieved annually were com pared across treatments; proactive areas were also com pared with a surrounding zone $5 \mathrm{~km}$ wide in which no culling was conducted. These analyses excluded data from Triplets D and $\mathbf{J}$ in 2002, because these areas only received their initial proactive culls in late 2002, while the majority of badger road kills occur in spring (Davies, Roper \& Sheperd son, 1987).

\section{Statistical analyses}

Data were analysed using Poisson regression and unba lanced ANOVA. All statistical models include triplet as a covariate. Several analyses investigated temporal trends in badger activity (e.g. changes in latrine density on successive surveys) under different culling treatments. Data from the reactive treatment were excluded from these analyses be cause this treatment was suspended part way through the study; however, descriptive data from reactive areas are presented. Average values quoted for reactive areas exclude Triplet $\mathbf{J}$ because no reactive culling was conducted there. All time periods used in analyses (e.g. days since the start of a culling operation) were represented as categorical vari ables.

Where appropriate, analyses adjusted for seasonal varia tion in badger activity. Seasons were defined such that February April was considered 'spring', May July was 'summer', August October was 'autumn' and November January was 'winter'.

Poisson regression analysis of the numbers of badgers captured in proactive areas considered two regions of each trial area: an 'outer' ( $\leq 1 \mathrm{~km}$ inside) and an 'inner $(>1 \mathrm{~km}$ inside) region. This analysis adjusted for the area of land accessible for culling in each region, as well as the numbers of traps deployed at setts. The locations of traps deployed away from setts were not recorded but the overall propor tion of badgers caught away from setts in the inner region $(18.4 \%)$ was similar to that in the outer region $(21.3 \%)$, suggesting that trap deployment away from setts did not differ systematically between regions.

We assessed the utility of field signs as indices of actual badger density by comparing the numbers of badgers captured on initial culls within $2 \times 2 \mathrm{~km}$ grid squares with the densities of setts and latrines recorded on pre cull surveys in the same squares. Poisson regressions, adjusting for triplet and the total area of the square falling inside the culling area, were used to compare field sign densities (measured as numbers per $\mathrm{km}^{2}$ available for surveying) with the numbers of adults captured. The results are reported for squares with $\geq 95 \%\left(3.8 \mathrm{~km}^{2}\right)$ inside the culling area, but the results were very similar when all squares were included, and when the total number of badgers (adults and cubs) was the outcome variable.

Further analyses explored the effects of culling on the persistence of particular setts between successive surveys; these are presented in Supplementary Material.

\section{Results}

\section{Trapping effort}

Proactive culling involved an estimated 160893 trap nights conducted over 51 operations, with an average of 298.5 traps deployed per night on each operation (Table 1). Average proactive capture effort was 40 trap night $\mathrm{s} \mathrm{km}^{-2}$ year $^{-1}$ over periods of 47 years. The 62 reactive culling operations for which data were available comprised a total of 21109 trap nights, with an average of 42.6 traps deployed per night on each operation.

As intended, the numbers of traps deployed at each sett exceeded the numbers of badgers caught in the majority of cases: on an average trap night, the proportion of setts where all available traps were occupied by badgers was $2.4 \%$ in proactive areas and $2.7 \%$ in reactive areas. This proportion declined rapidly through the course of an opera tion, from $9 \%$ (proactive) and 14\% (reactive) on the first night to $1 \%$ (both proactive and reactive) by the third night.

Non target species (e.g. pheasants Phasianus colchicus and grey squirrels Sciurus carolinensis) were caught on about $1 \%$ of trap nights in both proactive (Table 1) and reactive (Table 2 ) areas.

Interference with trapping operations was recorded on all 51 proactive culling operations and on 30 of 62 reactive culling operations for which data were available. Overall, such interference affected $8.1 \%$ of trap nights on proactive culling operations (Table 1), and $4.6 \%$ of trap nights on reactive culling operations (Table 2 ).

Occasionally, interference and capture of non target species together meant that no traps were available to 
Table 1 Capture rate, and interference with trapping, on culling operations conducted in proactive areas, summarized by triplet

\begin{tabular}{|c|c|c|c|c|c|c|c|}
\hline \multirow{2}{*}{\multicolumn{2}{|c|}{ Triplet Number of operation }} & \multirow[b]{2}{*}{ Area accessible to cull $\left(\mathrm{km}^{2}\right)$} & \multirow[b]{2}{*}{ Total trap nights ${ }^{a}$} & \multicolumn{2}{|c|}{ Number (\%) animals caught } & \multicolumn{2}{|c|}{ Number (\%) trap nights disrupted } \\
\hline & & & & Badgers $^{\mathrm{b}}$ & Other species ${ }^{\mathrm{C}}$ & Badgers released & Other interference \\
\hline $\bar{A}$ & 5 & 82.2 & 10751 & $362(3.9 \%)$ & $176(1.6 \%)$ & $12(0.1 \%)$ & $1232(11.5 \%)$ \\
\hline B & 7 & 88.2 & 26806 & $787(3.1 \%)$ & $181(0.7 \%)$ & $28(0.1 \%)$ & $1276(4.8 \%)$ \\
\hline $\mathrm{C}$ & 6 & 98.2 & 22111 & $964(4.7 \%)$ & $120(0.5 \%)$ & $36(0.2 \%)$ & $1637(7.4 \%)$ \\
\hline D & 4 & 75.9 & 13841 & $1051(8.4 \%)$ & $160(1.2 \%)$ & $12(0.1 \%)$ & $1177(8.5 \%)$ \\
\hline$E$ & $6^{d}$ & 77.9 & 19773 & $1459(8.2 \%)$ & $44(0.2 \%)$ & $22(0.1 \%)$ & $1922(9.7 \%)$ \\
\hline $\mathrm{F}$ & 5 & 55.8 & 14653 & $1177(9.9 \%)$ & $124(0.8 \%)$ & $68(0.5 \%)$ & $2581(17.6 \%)$ \\
\hline G & 5 & 74.0 & 13624 & $993(8.0 \%)$ & $87(0.6 \%)$ & $54(0.4 \%)$ & 1047 (7.7\%) \\
\hline $\mathrm{H}$ & 5 & 77.5 & 16023 & 588 (3.9\%) & 465 (2.9\%) & $15(0.1 \%)$ & $480(3.0 \%)$ \\
\hline । & 4 & 84.0 & 10887 & $659(6.6 \%)$ & $226(2.1 \%)$ & $7(0.1 \%)$ & $710(6.5 \%)$ \\
\hline J & 4 & 83.0 & 12424 & 846 (7.3\%) & $36(0.3 \%)$ & $23(0.2 \%)$ & 713 (5.7\%) \\
\hline Total & 51 & 796.8 & 160893 & $8886(6.1 \%)$ & $1619(1.0 \%)$ & $277(0.2 \%)$ & 12775 (7.9\%) \\
\hline
\end{tabular}

${ }^{\mathrm{a}}$ For operations where capture effort was not recorded daily, the number of trap nights was estimated by multiplying the number of traps set on the first night by the number of nights trapped.

${ }^{b}$ Per cent capture rate calculated as the number of badgers caught and despatched per available trap per night, where available traps are defined as those not disturbed and not occupied by another species.

'Percentages calculated as the proportion of all trap nights affected

dincludes two operations conducted in one culling year.

Table 2 Capture rate, and interference with trapping, on culling operations conducted in reactive areas

\begin{tabular}{|c|c|c|c|c|c|c|}
\hline \multirow[b]{2}{*}{ Triplet } & \multirow[b]{2}{*}{ Number of operations ${ }^{a}$} & \multirow[b]{2}{*}{ Total trap nights } & \multicolumn{2}{|c|}{ Number (\%) animals caught } & \multicolumn{2}{|c|}{ Number (\%) trap nights disrupted } \\
\hline & & & Badgers $^{b}$ & Other species ${ }^{c}$ & Badgers released & Other interference \\
\hline $\bar{A}$ & 7 & 1600 & $84(5.4 \%)$ & $29(1.8 \%)$ & $1(0.1 \%)$ & $1(0.1 \%)$ \\
\hline B & 5 & 3457 & $194(6.0 \%)$ & $56(1.6 \%)$ & $0(0.0 \%)$ & $169(4.9 \%)$ \\
\hline C & 13 & 2595 & $216(9.5 \%)$ & $12(0.5 \%)$ & $8(0.3 \%)$ & $312(12.0 \%)$ \\
\hline D & 4 & 1600 & $122(7.7 \%)$ & $7(0.4 \%)$ & $0(0.0 \%)$ & $2(0.1 \%)$ \\
\hline$E$ & 10 & 2468 & $188(7.7 \%)$ & $22(0.9 \%)$ & $1(0.0 \%)$ & $14(0.6 \%)$ \\
\hline $\mathrm{F}$ & 10 & 3967 & $435(11.8 \%)$ & $9(0.2 \%)$ & $14(0.4 \%)$ & $271(6.8 \%)$ \\
\hline G & 6 & 2549 & $256(10.4 \%)$ & $14(0.5 \%)$ & $1(0.0 \%)$ & $82(3.2 \%)$ \\
\hline $\mathrm{H}$ & 4 & 1898 & $159(9.1 \%)$ & $75(4.0 \%)$ & $2(0.1 \%)$ & $73(3.8 \%)$ \\
\hline । & 3 & 975 & $94(10.0 \%)$ & $10(1.0 \%)$ & $2(0.2 \%)$ & $19(1.9 \%)$ \\
\hline Total & & 21109 & 1748 (8.8\%) & $234(1.1 \%)$ & $29(0.1 \%)$ & $943(4.5 \%)$ \\
\hline
\end{tabular}

a'Number of operations' refers to the number of culls for which capture effort data were available, not the total number of operations performed (see text).

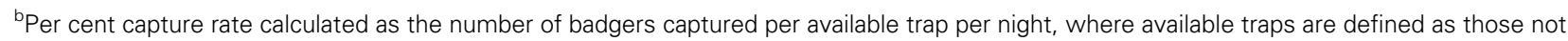
disturbed and not occupied by another species.

'Percentages calculated as the proportion of all trap nights affected.

No reactive culling was performed in Triplet J.

badgers at a particular sett, even though traps had been placed there. On an average night, $6.1 \%$ of trapped setts in proactive areas and $3.4 \%$ of those in reactive areas, were thus affected.

\section{Capture rates}

After accounting for interference and capture of non target species, on the first night of culling operations badgers were found in $20.1 \%$ of the traps in proactive areas and in $30.2 \%$ of the traps in reactive areas. Capture rates declined rapidly after the first night (Fig. 1a), averaging $6.1 \%$ in proactive areas (Table 1 ) and $8.8 \%$ in reactive areas (Table 2).
Within the proactive treatment, Poisson regression re vealed substantial variation in badger capture rates on different culling days, operations and trial area regions (Table 3). The number of badgers captured per operation declined on successive culls (Fig. 1b), while the proportion of badgers captured in the outer region of culling areas ( $\leq 1 \mathrm{~km}$ inside) increased (cull sequence $\times$ region interac tion, $\chi^{2} \quad 48.87$, d.f. $\quad 6, P<0.001$; Table 3). There was no similar variation in the spatial distribution of badger cap tures over the course of each operation (days since the start of operation $\times$ region interaction, $\chi^{2}$ 6.87, d.f. 6, $P \quad$ 0.65). The proportion of traps unavailable to badgers (through interference or capture of non target species) did not influence the capture rates in this analysis $\left(\chi^{2} \quad 0.002\right.$, d.f. $\quad 1, P \quad 0.97)$. 

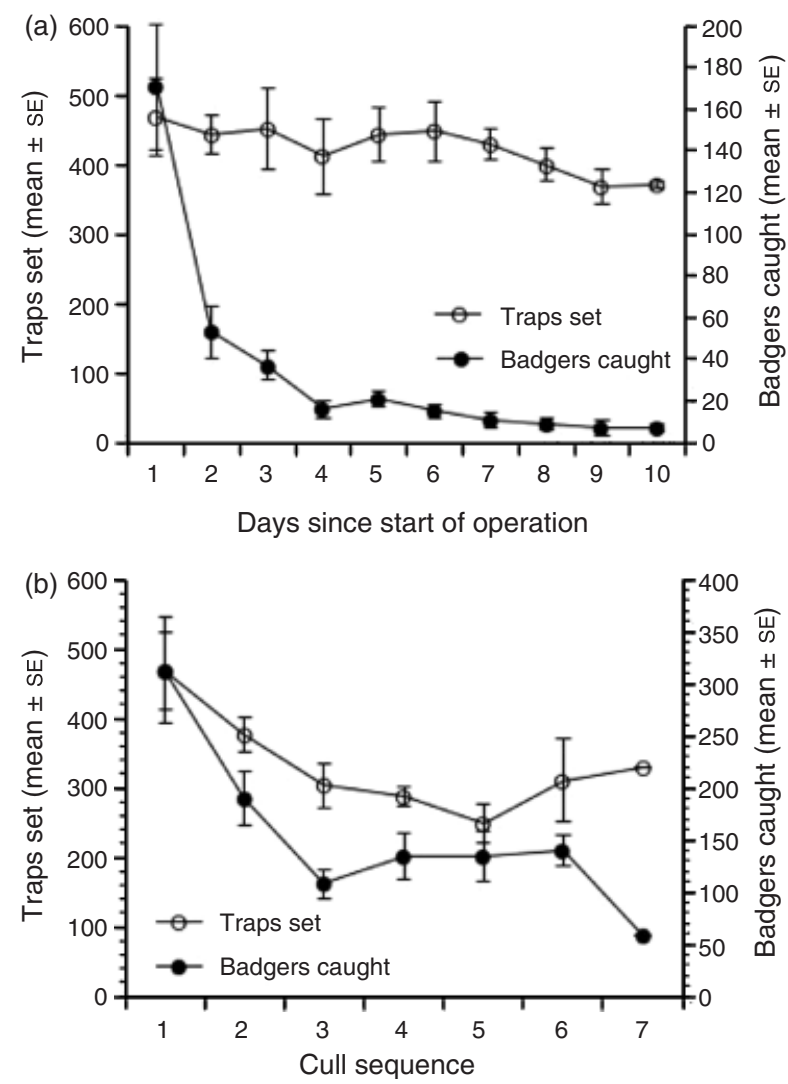

Figure 1 Variation in trapping effort and capture rate over time in proactive culling areas. (a) Numbers of traps set, and badgers Meles meles captured, on successive nights during initial proactive culling operations. (b) Number of traps set on the first night, and numbers of badgers caught (summed across all nights) for successive proactive culls. Data come from all operations for which data were available (see text).

\section{Relationships between field signs and badger captures}

Poisson regression revealed that the densities of badger field signs recorded on initial surveys were related to the numbers of adult badgers taken on initial culls from the same $4 \mathrm{~km}^{2}$ squares (Fig. 2). Odds ratios indicate that a doubling (100\% increase) in the density of field signs was associated with increases in adult captures of $92.9 \%$ [95\% confidence inter val (CI) $68.4120 .9 \%$ ] for active setts, $43.4 \%$ (CI $20.870 .2 \%$ ) for main setts, $99.5 \%$ (CI $72.5130 .7 \%$ ) for all setts, 84.7\% (CI 63.8 108.3\%) for active holes and 50.5\% (CI $35.866 .8 \%)$ for latrines $(P<0.001$ in all cases $)$.

\section{Effects of culling on badger activity measured on field surveys}

Before culling, the densities of badger field signs were comparable in areas subsequently allocated to the three treatments (Fig. 3). An unbalanced ANOVA comparing the densities of active setts across successive surveys, incor porating the effects of triplet, treatment (excluding reactive), survey season and survey number, showed a significant treatment effect $\left(F_{1,67} 44.1, P<0.001\right)$, with markedly lower sett densities in proactive areas (Fig. 3a); the treat ment $\times$ survey number interaction was not significant. By the fourth survey, the mean density of active setts in proactive areas $\left(1.29 \mathrm{~km}^{-2} \pm 0.61 \mathrm{SD}\right)$ was $59 \%$ lower than that in no culling areas $\left(3.16 \mathrm{~km}^{-2} \pm 1.36 \mathrm{sD}\right)$. Variation across triplets is shown in Fig. 4. By the fourth survey, the mean density of active setts in reactive areas $\left(2.77 \mathrm{~km}^{-2}\right.$ $\pm 0.98 \mathrm{SD}$ ) was $17 \%$ lower than that in nine matched no culling areas $\left(3.34 \mathrm{~km}^{-2} \pm 1.31 \mathrm{sD}\right)$.

The number of active holes (all setts combined) per $\mathrm{km}^{2}$ gives an alternative index of badger abundance (Fig. 2). On the fourth survey, the mean density of active holes in proactive areas $\left(2.83 \mathrm{~km}^{-2} \pm 1.52 \mathrm{SD}\right)$ was $69 \%$ lower than that in no culling areas $\left(9.18 \mathrm{~km}^{-2} \pm 4.92 \mathrm{sD}\right)$, and that in reactive areas $\left(7.23 \mathrm{~km}^{-2} \pm 3.26 \mathrm{SD}\right)$ was $26 \%$ lower than that in nine matched no culling areas $\left(9.81 \mathrm{~km}^{-2} \pm 4.78 \mathrm{sD}\right)$.

Latrine density showed a pattern similar to that for setts. An unbalanced ANOVA comparing latrine densities across successive surveys, incorporating the effects of triplet, treat ment (excluding reactive) and survey number, showed a significant treatment $\times$ survey interaction $\left(F_{4,66} \quad 4.54\right.$, $P$ 0.003), indicating different temporal patterns in the two treatments. Latrine density declined markedly in proac tive areas, but not in no culling areas (Fig. 3b). By the fourth survey, the mean latrine density in proactive areas $\left(2.49 \mathrm{~km}^{-2} \pm 1.50 \mathrm{SD}\right)$ was $73 \%$ lower than that in no culling areas $\left(9.14 \mathrm{~km}^{-2} \pm 5.26 \mathrm{sD}\right)$, and the latrine density in reactive areas $\left(7.09 \mathrm{~km}^{-2} \pm 4.55 \mathrm{sD}\right)$ was $26 \%$ lower than that in the nine matched no culling areas $\left(9.56 \mathrm{~km}^{-2} \pm 5.39 \mathrm{SD}\right)$. Survey season did not explain variation in latrine density in this analysis $\left(\begin{array}{lll}F_{3,76} & 0.35, P & 0.79\end{array}\right)$.

\section{Effects of culling on badger activity measured by bait marking}

The numbers of bait returns per $\mathrm{km}^{2}$ appeared to be influenced by culling (Fig. 3c). Bait return density inside proactive areas was on average $64 \%$ lower than that in matched no culling areas (range $3676 \%$ lower) and $76 \%$ lower than that in adjoining unculled areas (range 75 77\%). Reactive culling was associated with a $53 \%$ reduction in bait return density.

\section{Effects of culling on retrieval of road-killed badgers}

Culling also influenced retrieval rates of badgers killed in road traffic accidents. In the road traffic accident survey as a whole, carcass retrieval rates increased over time, largely due to increasing effort (Fig. 3d). The same pattern was observed in no culling areas, and around proactive areas, but not inside proactive areas where retrieval rates were consistently low (Fig. 2d). A Poisson regression analysis of the numbers of carcasses retrieved in proactive and no culling areas (including triplet, area, year and treatment as covariates) showed a significant treatment $\times$ year 
Table 3 Predictors of the numbers of badgers captured in the inner and outer regions of proactive culling areas, revealed by Poisson regression

\begin{tabular}{|c|c|c|c|c|}
\hline Predictor & Odds ratio $(95 \% \mathrm{Cl})$ & $\chi^{2}$ & d.f. & $P$ \\
\hline Triplet & & 467.8 & 9 & $<0.001$ \\
\hline Cull sequence (initial to seventh) & & 111.1 & 6 & $<0.001$ \\
\hline Days since start of operation & & 2900 & 9 & $<0.001$ \\
\hline Traps available (In transformed) & $1.34(1.221 .47)$ & 40.66 & 1 & $<0.001$ \\
\hline Area accessible (In transformed) & $3.20(1.855 .51)$ & 17.94 & 1 & $<0.001$ \\
\hline Active setts (In transformed) & $1.28(1.121 .46)$ & 13.24 & 1 & $<0.001$ \\
\hline Season & & 44.84 & 2 & $<0.001$ \\
\hline Summer versus winter & $1.41(1.271 .56)$ & & & \\
\hline Autumn versus winter & $1.24(1.091 .42)$ & & & \\
\hline Region (outer or inner) & & 0.04 & 1 & 0.84 \\
\hline Cull sequence $\times$ region & & 48.87 & 6 & $<0.001$ \\
\hline \multicolumn{5}{|l|}{ Outer versus inner } \\
\hline Initial cull & $1.61(0.892 .89)$ & & & \\
\hline Second cull & $1.57(0.882 .81)$ & & & \\
\hline Third cull & $2.24(1.254 .02)$ & & & \\
\hline Fourth cull & $2.51(1.404 .48)$ & & & \\
\hline Fifth cull & $2.45(1.36 \quad 4.42)$ & & & \\
\hline Sixth cull & $2.07\left(\begin{array}{lll}1.13 & 3.81\end{array}\right)$ & & & \\
\hline Seventh cull & & & & \\
\hline
\end{tabular}

Data are from the period when details of capture effort and success were recorded for every sett trapped (June 2002 to October 2006).
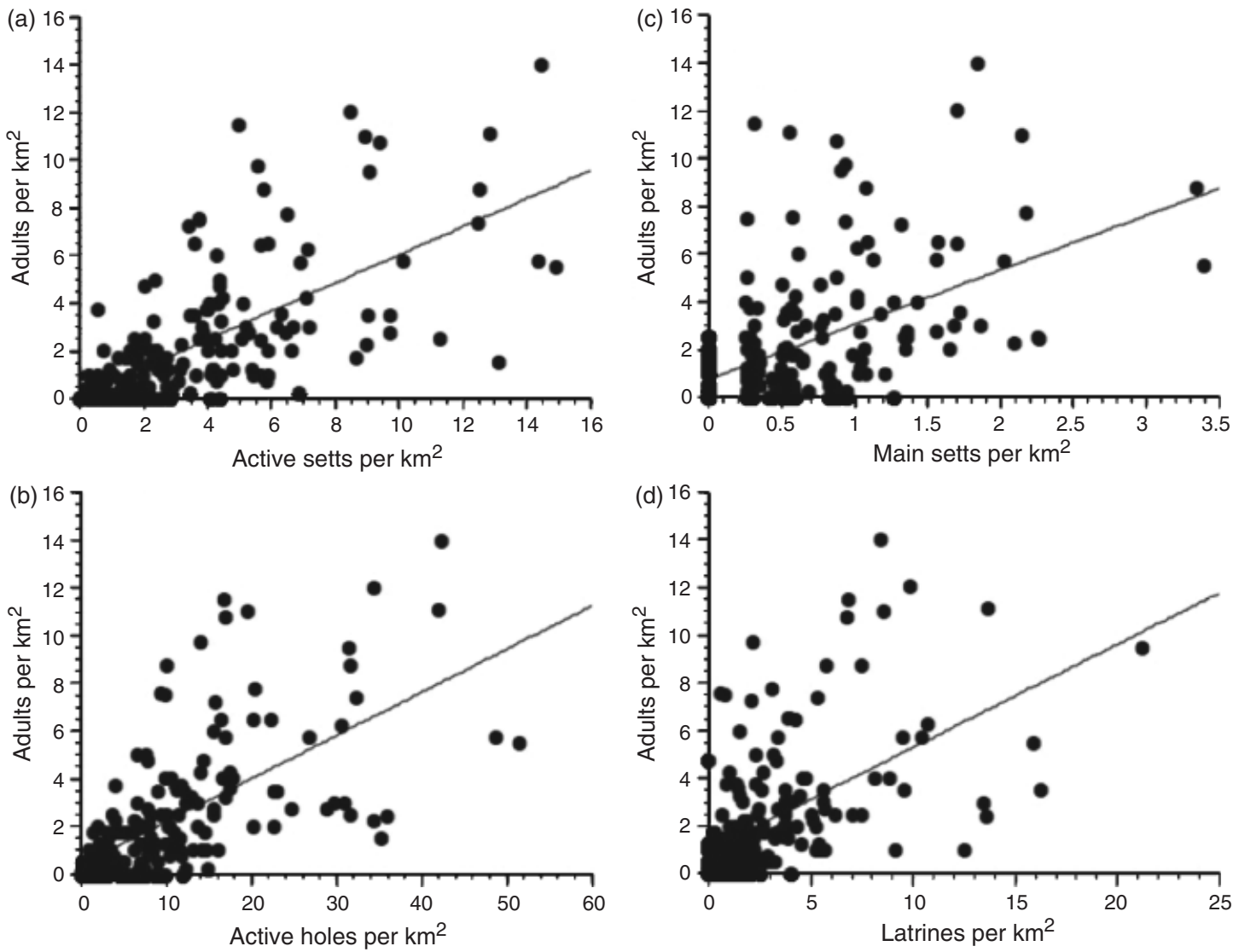

Figure 2 Relationships between the densities of badger Meles meles field signs and the numbers of badgers captured. Graphs compare the densities of adult badgers captured on initial culls, in $2 \times 2 \mathrm{~km}$ grid squares, with the corresponding densities of (a) active setts, (b) active holes, (c) main setts and (d) latrines recorded on initial (pre cull) surveys. 

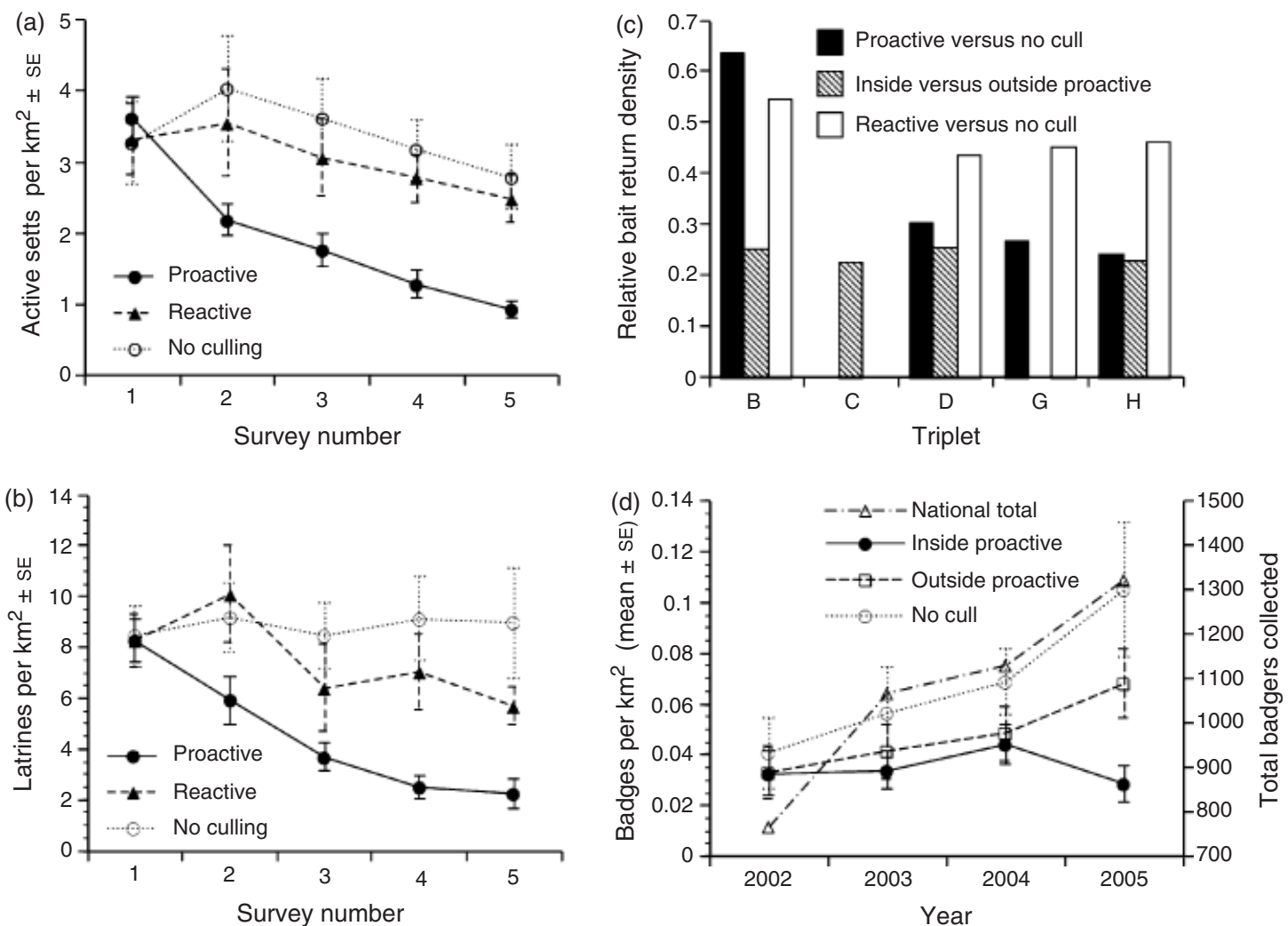

Figure 3 Effects of culling on indices of badger Meles meles activity. Graphs indicate the densities of (a) active setts and (b) badger latrines recorded on successive field surveys. Reactive culling was suspended immediately before the second survey in two triplets, and between the second and third surveys in the remaining seven triplets (no reactive culling occurred in Triplet $\mathrm{J}$ ); there is no evidence of subsequent recovery of the badger population. Graph (c) shows the densities of bait returns in culling areas, expressed relative to the densities recorded in matched areas not subjected to culling, in five triplets where badger home ranges were mapped by bait marking. Graph (d) shows the total numbers of road killed badgers retrieved nationally, and numbers retrieved per $\mathrm{km}^{2}$ inside, and up to $5 \mathrm{~km}$ outside, seven proactive culling areas and inside matched no culling areas.

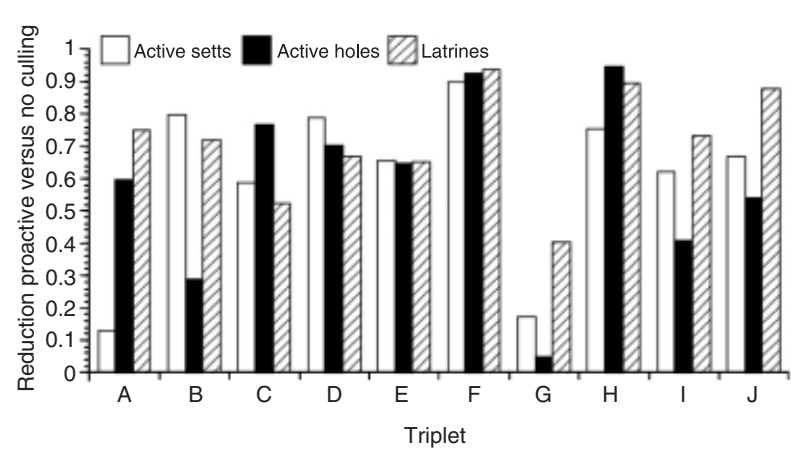

Figure 4 Consistency of proactive culling effects across triplets Effects on field sign densities were estimated by calculating, for each trial area, the proportional change in density between the first and the fourth survey, and then comparing this change in proactive and no culling areas.

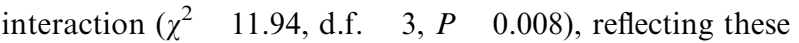
different temporal patterns in the two treatments. By 2005, the average density of road killed badgers retrieved inside seven proactive culling areas $\left(0.029 \mathrm{~km}^{-2} \pm 0.017 \mathrm{sD}\right)$ was
$73 \%$ lower than that recorded in the corresponding no culling areas $\left(0.105 \mathrm{~km}^{-2} \pm 0.027\right)$, and $58 \%$ lower than that recorded in the $5 \mathrm{~km}$ zone surrounding proactive areas $\left(0.068 \mathrm{~km}^{-2} \pm 0.014\right)$. In 2003 , the last year of reactive culling, the average density of road killed badgers was $9.8 \%$ lower inside six reactive areas $\left(0.061 \mathrm{~km}^{-2} \pm 0.023 \mathrm{sD}\right)$ than in six matched no culling areas $\left(0.068 \mathrm{~km}^{-2} \pm 0.037 \mathrm{sD}\right)$.

\section{Discussion}

The data presented here reveal substantial effects of culling on all indices of badger abundance, consistent with the original aims of the RBCT (Bourne et al., 1998). For example, proactive culling was associated with a $73 \%$ reduction in latrine density, a $69 \%$ reduction in the density of active holes, a $6476 \%$ reduction in the density of bait returns and a $73 \%$ reduction in the density of road killed badgers. Different indices provided roughly comparable estimates within each triplet (Fig. 4). While the density reductions achieved by proactive culling varied across tri plets, these appeared not to reflect variation in the overall rates of capture or interference (Table 1) or the efficacy of 
initial proactive culls as estimated by Smith \& Cheeseman (2007).

Activity reductions associated with reactive culling were smaller than those for proactive culling: average values were $26 \%$ for latrine density, $32 \%$ for active hole density, $53 \%$ for bait returns and $10 \%$ for road kill density. Interestingly, indices provide no evidence of population recovery follow ing suspension of the reactive strategy (Fig. 3).

All measures indicate substantial effects of culling on badger population densities, but the precise magnitude of the effect is difficult to measure using these methods. Although the densities of field signs were correlated with the numbers of badgers taken on initial culls (Fig. 2), these relationships cannot be used to calibrate the density indices because the relationship between capture rate and true density is unknown. New methods have been developed recently for directly (Hounsome et al., 2005) and indirectly (Tuyttens et al., 2001; Wilson et al., 2003a,b; Frantz et al., 2004) enumerating badgers, but these were developed after the start of the RBCT and so could not be used to measure temporal trends.

Despite the limitations of the survey methods available, the broad consistency of our findings across multiple meth odologies is reassuring. In culled areas, the number of setts used by each badger is elevated (Cheeseman et al., 1993), while the use of latrines is reduced (Hutchings, Service \& Harris, 2002); such behavioural changes probably contrib uted to the variation between measures of culling impacts shown in Fig. 4.

The proportion of badgers caught close to the culling area boundary increased on successive proactive culls. This provides evidence of immigration into the areas cleared by culling, and is consistent with the evidence of population reduction immediately outside culling area boundaries documented by Woodroffe et al. (2006a). This evidence of immigration shows that the indices of local badger activity were probably generated by populations comprising new immigrants as well as animals missed by culling operations. Hence, while field signs provide valuable indicators of the broad reductions in badger density achieved by culling, they almost certainly underestimate the proportion of the origi nal population that was removed.

Reproduction was more important than immigration in the repopulation of a smaller area cleared by culling at Woodchester Park (Cheeseman et al., 1993). In our proac tive areas, however, repeated culling would have countered population growth through breeding. It is likely that the proactive areas functioned as 'sink' patches influencing population dynamics over larger areas, as has been de scribed for several other species (Mace \& Waller, 1998; Woodroffe \& Frank, 2005). This 'vacuum effect' has been linked to elevated prevalence of $M$. bovis infection in badgers close to culling area boundaries, and increased TB incidence in neighbouring cattle (Woodroffe et al., 2006b). Culling methods such as snaring and gassing, which have been considered for future use because of their potentially greater efficiency at removing badgers (Defra, 2005), are likely to have similar or greater consequences for source sink dynamics. Such methods could therefore be expected to generate 'edge effects' on disease similar to those documen ted in the RBCT.

Interference with culling activities occurred on all proac tive and many reactive culling operations. However, the level of interference was not found to explain variation in the numbers of badgers captured.

Taken together, our analyses indicate that proactive culling substantially reduced badger population densities. Nevertheless, this treatment reduced overall cattle TB in cidence by only $19 \%$ (95\% CI $6.230 \%$, Donnelly et al., 2006). Immigration into culled areas, along with disruption of social and territorial organization, appears to cause increased contact among badgers and hence elevated $M$. bovis prevalence (Woodroffe et al., 2006a,b). This increased prevalence, combined with expanded ranging behaviour likely to increase contact between badgers and cattle herds (Woodroffe et al., 2006a), may explain the limited capacity of substantial badger population reduction to achieve com parable reductions in TB risk for cattle.

The reductions in badger population density described here were achieved by a systematic and coordinated effort, conducted by specialist staff and sustained over several years. Any culling policy developed in future would prob ably need to be conducted with a similar, or greater, intensity and would therefore require comparable effort. Even if culling efficiency could be improved somewhat, modelling suggests that further reductions in cattle TB incidence could be marginal (Smith et al., 2001; Cox et al., 2005), and detrimental edge effects would still be likely. Because substantial reduction of badger populations over wide areas requires massive effort, generates only modest reductions in cattle TB incidence in culled areas and elevates cattle TB incidence in neighbouring areas, this approach appears to have limited value for TB control in British cattle.

\section{Acknowledgements}

This study was funded and implemented by the Department for Environment, Food and Rural Affairs (Defra). We gratefully acknowledge the hard work of the Defra Wildlife Unit, which conducted all RBCT fieldwork, and the Central Science Laboratory, which contributed to the survey of road killed badgers. We also wish to thank the many land holders who allowed data collection on their land.

\section{References}

Ballantyne, E.E. \& O’Donoghue, J.G. (1954). Rabies control in Alberta. J. Am. Vet. Med. Assoc. 125, 316326.

Barlow, N.D. (1996). The ecology of wildlife disease control: simple models revisited. J. Appl. Ecol. 33, 303314.

Bourne, J., Donnelly, C., Cox, D., Gettinby, G., McInerney, J.P., Morrison, I. \& Woodroffe, R. (1998). Towards a sustainable policy to control TB in cattle a scientific 
initiative. First report of the independent scientific group on cattle TB. London: Ministry of Agriculture, Fisheries \& Food.

Cheeseman, C.L., Mallinson, P.J., Ryan, J. \& Wilesmith, J.W. (1993). Recolonisation by badgers in Gloucestershire. In The badger: 78 93. Hayden, T.J. (Ed.). Dublin: Royal Irish Academy.

Cox, D.R., Donnelly, C.A., Bourne, F.J., Gettinby, G., McInerney, J.P., Morrison, W.I. \& Woodroffe, R. (2005). Simple model for tuberculosis in cattle and badgers. Proc. Natl. Acad. Sci. USA 102, 1758817593.

Cresswell, W.J. (2001). Report of the independent audit of surveying and badger social group territory delineation procedures used in the randomised badger culling trial. London: Defra.

Davies, J.M., Roper, T.J. \& Sheperdson, D.J. (1987). Seaso nal distribution of road kills in the European badger (Meles meles). J. Zool. (Lond.) 211, 525529.

Defra (2005). Controlling the spread of bovine tuberculosis in cattle in high incidence areas in England: badger culling. A consultation document issued by the Department for Environment, Food and Rural Affairs. London: Defra.

Delahay, R.J., Brown, J.A., Mallinson, P.J., Spyvee, P.D., Handoll, D., Rogers, L.M. \& Cheeseman, C.L. (2000). The use of marked bait in studies of the territorial organization of the European badger (Meles meles). Mammal Rev. 30, 7387.

Dobson, A. \& Meagher, M. (1996). The population dynamics of brucellosis in the Yellowstone National Park. Ecology 77, 10261036.

Donnelly, C.A., Woodroffe, R., Cox, D.R., Bourne, F.J., Cheeseman, C.L., Wei, G., Gettinby, G., Gilks, P., Jenkins, H., Johnston, W.T., Le Fevre, A.M., McInerney, J.P. \& Morrison, W.I. (2006). Positive and negative effects of widespread badger culling on cattle tuberculosis. Nature 439, 843846.

Donnelly, C.A., Woodroffe, R., Cox, D.R., Bourne, J., Gettinby, G., Le Fevre, A.M., McInerney, J.P. \& Morri son, W.I. (2003). Impact of localized badger culling on TB incidence in British cattle. Nature 426, 834837.

Frantz, A.C., Schaul, M., Pope, L.C., Fack, F., Schley, L., Muller, C.P. \& Roper, T.J. (2004). Estimating population size by genotyping remotely plucked hair: the Eurasian badger. J. Appl. Ecol. 41, 985995.

Griffin, J.M., Clegg, T.A., Quigley, F., Hammond, R.F., McGrath, G., Sleeman, D.P., Costello, E. \& O'Boyle, I. (2003). The four area badger study: 1997 2002. In Selected papers 2002 2003: 1 12. Collins, J.D. \& Hammond, R.F. (Eds). Dublin: Veterinary Epidemiology and Tuberculosis Investigation Unit, University College Dublin.

Griffin, J.M., Williams, D.H., Kelly, G.E., Clegg, T.A., O'Boyle, I., Collins, J.D. \& More, S.J. (2005). The impact of badger removal on the control of tuberculosis in cattle herds in Ireland. Preventive Vet. Med. 67, 237266.

Hounsome, T.D., Young, R.P., Davison, J., Yarnell, R.W., Trewby, I.D., Garnett, B.T., Delahay, R.J. \& Wilson, G.J.
(2005). An evaluation of distance sampling to estimate badger (Meles meles) abundance. J. Zool. (Lond.) 266, 8187.

Hutchings, M.R., Service, K.M. \& Harris, S. (2002). Is population density correlated with faecal and urine scent marking in European badgers (Meles meles) in the UK? Mammal. Biol. 67, 286293.

Kirkwood, J.K. (2000). Humaneness of MAFF's badger dis patch procedures. London: Ministry of Agriculture, Fish eries and Food.

Krebs, J.R., Anderson, R., Clutton Brock, T., Morrison, I., Young, D., Donnelly, C., Frost, S. \& Woodroffe, R. (1997). Bovine tuberculosis in cattle and badgers. London: HMSO.

Mace, R.D. \& Waller, J.S. (1998). Demography and popula tion trend of grizzly bears in the Swan Mountains, Mon tana. Conserv. Biol. 12, 10051016.

Sadlier, L.M.J., Webbon, C.C., Baker, P.J. \& Harris, S. (2004). Methods of monitoring red foxes Vulpes vulpes and badgers Meles meles: are field signs the answer? Mammal Rev. 34, 7598.

Smith, G. \& Cheeseman, C.L. (2007). An assessment of trapping efficacy during the initial proactive culls in the randomised badger culling trial Vet. Rec. 160, 723726.

Smith, G.C., Cheeseman, C.L., Wilkinson, D. \& Clifton Hadley, R.S. (2001). A model of bovine tuberculosis in the badger Meles meles: the inclusion of cattle and the use of a live test. J. Appl. Ecol. 38, 520535.

Thornton, P. (1988). Density and distribution of badgers in South West England a predictive model. Mammal Rev. 18, 123.

Tuyttens, F.A.M., Long, B., Fawcett, T., Skinner, A., Brown, J.A., Cheeseman, C.L., Roddam, A.W. \& Macdonald, D.W. (2001). Estimating group size and population density of Eurasian badgers Meles meles by quantifying latrine use. J. Appl. Ecol. 38, 11141121.

Wilson, G.J., Delahay, R.J., de Leeuw, A.N.S., Spyvee, P.D. \& Handoll, D. (2003a). Quantification of badger (Meles meles) sett activity as a method of predicting badger numbers. J. Zool. (Lond.) 259, 4956.

Wilson, G.J., Frantz, A.C., Pope, L.C., Roper, T.J., Burke, T.A., Cheeseman, C.L. \& Delahay, R.J. (2003b). Estima tion of badger abundance using faecal DNA typing. J. Appl. Ecol. 40, 658666.

Woodroffe, R., Bourne, F.J., Cheeseman, C.L., Cox, D.R., Donnelly, C.A., Gettinby, G., McInerney, J.P. \& Morri son, W.I. (2005a). Welfare of badgers (Meles meles) sub jected to culling: development and evaluation of a closed season. Anim. Welfare 14, 1925.

Woodroffe, R., Bourne, F.J., Cheeseman, C.L., Cox, D.R., Donnelly, C.A., Gettinby, G., McInerney, J.P. \& Morri son, W.I. (2005b). Welfare of badgers (Meles meles) sub jected to culling: patterns of trap related injury. Anim. Welfare 14, 1117.

Woodroffe, R., Donnelly, C.A., Cox, D.R., Bourne, F.J., Cheeseman, C.L., Delahay, R.J., Gettinby, G., McInerney, 
J.P. \& Morrison, W.I. (2006a). Effects of culling on badger (Meles meles) spatial organization: implications for the control of bovine tuberculosis. J. Appl. Ecol. 43, 110 .

Woodroffe, R., Donnelly, C.A., Jenkins, H.E., Johnston, W.T., Cox, D.R., Bourne, F.J., Cheeseman, C.L., Delahay, R.J., Clifton Hadley, R.S., Gettinby, G., Gilks, P., Hewin son, R.G., McInerney, J.P. \& Morrison, W.I. (2006b). Culling and cattle controls influence tuberculosis risk for badgers. Proc. Natl. Acad. Sci. USA 103, 1471314717.

Woodroffe, R. \& Frank, L.G. (2005). Lethal control of African lions (Panthera leo): local and regional population impacts. Anim. Conserv. 8, 9198. 